\title{
Mediação e Arbitragem na resolução de conflitos sobre preços dos contratos de parcerias empresariais no agronegócio
}

\author{
Mediation and Arbitration in the resolution of conflicts on prices of business partnership contracts \\ in agribusiness \\ Mediación y Arbitraje en la resolución de conflictos sobre los precios de los contratos de asociación \\ empresarial en la agroindustria
}

Recebido: 26/02/2021 | Revisado: 05/03/2021 | Aceito: 19/03/2021 | Publicado: 25/03/2021

Diego Henrique Damasceno Coêlho
ORCID: https://orcid.org/0000-0002-1553-0958
Universidade Federal Fluminense, Brasil
E-mail: diegocoelho.contato@ gmail.com
Camila Braga Corrêa
ORCID: https://orcid.org/0000-0002-4335-6205
Centro Universitário UNIFACIG, Brasil
E-mail: camilabragacorrea@ gmail.com
Gilvan Luiz Hansen
ORCID: https://orcid.org/0000-0002-0785-5752
Universidade Federal Fluminense, Brasil
E-mail: gilvanluizhansen@id.uf.br

\begin{abstract}
Resumo
O presente artigo traz à discussão a funcionalidade da mediação e da arbitragem como instrumentos alternativos de solução de controvérsias potenciais nos conflitos de interesse oriundos do setor empresarial do agronegócio, com enfoque nos valores e preços de contratos entre pessoas jurídicas, onde o intuito é a harmonização dos interesses comuns e privados, solucionando questões econômicas contratuais, através de procedimentos mais céleres, desburocratizados e eficazes, em vistas à prestação de decisões atentas às personalidades dos casos, colaborando também com a redução da judicialização de conflitos, utilizando uma construção metodológica de pesquisas bibliográficas, com revisão da legislação, da doutrina e da jurisprudência já desenvolvida até o presente momento, num procedimento quantitativo-qualificativo-descritivo de conceitos e resultados, contextualizando modelos de contrato desta senda da indústria, que tradicionalmente vincula-se estreitamente a interesses de governos, legislações internacionais e trespasses financeiros de grande monta. Os resultados obtidos comprovam que, face a legislações internacionais conflitantes, a mediação e arbitragem são os métodos mais benéficos para o equilíbrio de interesses das partes dos contratos.
\end{abstract}

Palavras-chave: Mediação; Arbitragem; Agronegócio; Contratos; Conflitos.

\begin{abstract}
The present article aims to discuss about the functionality of mediation and arbitration as alternative instruments for solving potential controversies in conflicts of interests from the business sector of agribusiness, focusing on the values and prices of the contracts between private entities, where the emphasis is to harmonize common interests as well as the private ones, by solving contractual and economic issues, through faster, de-bureaucratic and effective procedures, in the sense to produce decisions closest to the personalities of the interested ones, also collaborating with the reduction of the judicialization of cases, using a methodological construction of bibliographical researches, with revisions of the legislations, doctrines and jurisprudence recently developed, in a quantitative and descriptive procedure of concepts and results, contextualizing contract models of this industrial sector, which is traditionally close to governments, international legislations and huge amount of financial concentration. The results show that, in the face of conflicting international legislation, mediation and arbitration are the most beneficial methods for harmonizing the parties' interests in contracts.
\end{abstract}

Keywords: Mediation; Arbitration; Agribusiness; Contracts; Conflicts.

\section{Resumen}

En este artículo se analiza la funcionalidad de la mediación y el arbitraje como instrumentos alternativos para la resolución de potenciales controversias en conflictos de interés derivados del sector empresarial agroindustrial, con un enfoque en los valores y precios de los contratos entre personas jurídicas, donde el propósito es la armonización de los e intereses privados, resolviendo cuestiones económicas contractuales, a través de procedimientos más rápidos, menos 
burocráticos y efectivos, con el fin de brindar decisiones atentas a las personalidades de los casos, colaborando también con la reducción de la judicialización de conflictos, utilizando una construcción metodológica de bibliografía. investigación, con revisión de legislación, doctrina y jurisprudencia ya desarrollada hasta la fecha, en un procedimiento cuantitativo-calificativo-descriptivo de conceptos y resultados, contextualizando modelos de contrato de esta trayectoria industrial, que tradicionalmente está muy ligada a los intereses gubernamentales, legi transacciones internacionales y grandes transferencias financieras. Los resultados obtenidos muestran que, ante una legislación internacional conflictiva, la mediación y el arbitraje son los métodos más beneficiosos para equilibrar los intereses de las partes de los contratos.

Palabras clave: Mediación; Arbitraje; Agroindustria; Contratos; Conflictos.

\section{Introdução}

Inserido num contexto em que a cadeia produtiva tem nos contratos agrários um importante elo e que as circunstâncias da agricultura brasileira têm sofrido alterações nas últimas décadas, as previsões legais deixaram de prestar segurança e proteção, conforme preceitua o Estatuto da Terra, de 1964, aos trabalhadores/agricultores visualizados como hipossuficientes ${ }^{1}$ para diante da complexidade das relações negociais estabelecidas nesta seara, privilegiarem as empresas que atuam no agronegócio. Consequentemente ao aumento significativo do setor agroindustrial, as relações por ele estabelecidas se tornaram mais complexas devido à vasta gama de problemas potenciais que este setor enfrenta, existindo a necessidade de solução das disputas ${ }^{2}$ em modos mais rápidos e justos possíveis (Olivier de Sardan, 2009, p. 118). Logo, as pessoas jurídicas contratantes no campo do agronegócio começaram a inserir em seus contratos empresariais cláusulas de mediação e arbitragem, apresentando uma estrutura flexível na qual as partes podem resolver questões difíceis, sem a necessidade de judicializar questões.

A mediação pode ser definida como "um dos instrumentos de pacificação de natureza autocompositiva e voluntária, no qual um terceiro, imparcial, atua, de forma ativa ou passiva, como facilitador do processo de retomada do diálogo entre as partes, antes ou depois de instaurado o conflito" (Cahali, 2012, p. 57), de modo que num primeiro momento, coloca-se as partes "frente a frente", e, em um segundo momento "o mediador propõe as bases para o desenvolvimento das negociações e intervém durante todo o processo, com o objetivo de concitar as partes a aproximar seus pontos de vista sem, contudo, impor uma solução" (Cretella Neto, 2004, p.3). Está estabelecida na Lei no 13.140/2.015 e o seu conceito legal está insculpido no art. $1^{\text {o3 }}$ do referido diploma legal. Por outro lado, a arbitragem é conceituada como "o meio privado e alternativo de solução de conflitos referentes aos direitos patrimoniais e disponíveis através do árbitro, normalmente um especialista na matéria controvertida, que apresentará uma sentença arbitral” (Sacavone Junior, 2010, p. 15), e está regulada pela Lei nº 9.307/96, que traz em seu art. $1^{04}$ a abrangência da arbitragem, cuja culminância é a produção de uma sentença possuidora da mesma força de uma sentença judicial.

Muito comuns nos Estados Unidos e no bloco europeu, onde os governos regulam diretamente (através de agências) a produção agrícola, a mediação e a arbitragem aplicadas ao agronegócio tem se estruturado no Brasil, majoritariamente entre pessoas jurídicas empresariais, tais como fornecedores de insumos e produtores, os quais produzem contratos já contendo

${ }^{1}$ Conforme Alves, et al., "dos 191 milhões de brasileiros, apenas 29,8 milhões estão no meio rural, ou seja, apenas 15,6\% da população brasileira. Grande parte dos rurícolas se concentra no Nordeste, 14,3 milhões, 47,8\% de todos eles. A segunda região de meio rural mais populoso é o Sudeste, com 5,7 milhões de habitantes, 19,1\% do total. O Centro-Oeste é um grande vazio, com 1,6 milhão. O Norte e o Sul com 4,2 e 4,1 milhões de habitantes respectivamente - praticamente se equivalem, sendo primeiro um grande vazio demográfico, com a população se urbanizando rapidamente, embora tenha se retardado nesse aspecto".

${ }^{2}$ Segundo o pensamento de Olivier de Sardan (2009) deve ser proposta uma antropologia de governança, traduzida pela utilização das tecnologias de mediação e conciliação dadas por normas implícitas de comportamento coletivo e normas jurídicas, que compõem "normas práticas" melhor adaptadas às interfaces locais, ou seja, no espaço onde as pessoas adquirem, produzem e negociam bens.

${ }^{3}$ Art. $1^{\circ}$. Esta Lei dispõe sobre a mediação como meio de solução de controvérsias entre particulares e sobre a autocomposição de conflitos no âmbito da administração pública. Parágrafo único. Considera-se mediação a atividade técnica exercida por terceiro imparcial sem poder decisório, que, escolhido ou aceito pelas partes, as auxilia e estimula a identificar ou desenvolver soluções consensuais para a controvérsia.

${ }^{4}$ Art. $1^{\circ}$ As pessoas capazes de contratar poderão valer-se da arbitragem para dirimir litígios relativos a direitos patrimoniais disponíveis. 
cláusulas mediadoras ou arbitrais, como forma principal de solução de conflitos, associadas a previsões de seguro (insurance) e resseguros (reinsurance).

Neste contexto, o presente trabalho tem por objetivo situar o cumprimento de contratos do agronegócio, ao observar o panorama e as peculiaridades do agronegócio no Brasil, os desdobramentos dos contratos no campo e os fatores que podem impactar o integral cumprimento dos mesmos, bem como o papel dos processos de resolução alternativa de conflitos neste contexto. Ao final da pesquisa, conclui-se que os mecanismos alternativos de resolução de disputas podem sem aplicados ao agronegócio e têm o condão de aperfeiçoar as relações interpessoais e comerciais, com objetivos que capazes de assegurar o diálogo e a boa convivência, em relações de parcerias justas e duradouras, ao passo que efetivam o cumprimento das obrigações contratuais.

\section{Metodologia}

Para a realização da presente pesquisa, foi selecionada uma metodologia mista e integradora, que abarcou a revisão de dados quantitativos (Pereira, et al., 2018) e a recuperação, seleção e fichamento de informações qualitativas (Koche, 2011) atreladas ao recorte temático, por meio do método hipotético-dedutivo, o qual permitiu formular questionamentos sobre os contextos nos quais se devolve o agronegócio e suas características peculiares no Brasil. Para tanto, o trabalho foi organizando segundo um mote eminentemente interdisciplinar, abrangendo o Direito e as Ciências Políticas, Econômicas e Sociais, no intento de se aprofundar na moldura jurídica, na economia e nos procedimentos privados e interpessoais aplicados à mediação e à arbitragem em contratos do agronegócio.

Desse modo, foram realizadas pesquisas bibliográficas, com revisão da legislação, da doutrina e da jurisprudência, já desenvolvidas até o presente momento, num procedimento quantitativo-qualificativo-descritivo de conceitos e resultados (Ludke \& Andre, 2013), voltados para a difusão de conhecimentos, saberes, práticas, habilidades e competências interdisciplinares, que possibilitem mais ampla aplicação dos mecanismos de mediação e arbitram na resolução de conflitos sobre preços dos contratos de parcerias no agronegócio.

\section{Ciclo de Produção na Indústria do Agronegócio}

O agronegócio, também conhecido em inglês como "agribusiness", compreende o setor empresarial agrário, principalmente em agricultura e em pecuária intensiva, abarcando as relações comerciais e industriais (Borges, 2012, p. 33). No Brasil, o agronegócio predominantemente se desenvolve, desde a colonização, em torno do modelo de monocultoras, em grandes propriedades privadas (fazendas), caracterizadas por suas enormes extensões territoriais, chamadas de latifúndios (Marques, 2015).

Apesar das raízes históricas, os latifúndios modernos caracterizam-se precipuamente pela utilização de tecnologias avançadas em contrapartida à paulatina mitigação da mão de obra, seguindo um modelo de produção voltado para a exportação de produtos considerados commodities ${ }^{5}$, como destaque para a soja, o milho, o algodão, a pecuária leiteira e de corte (IBGE, 2018). Nessa escala produtiva, vários agentes econômicos atuam em momentos específicos, segmentando o setor em partes inter-relacionadas, porém com características bastante peculiares a cada uma delas, capazes de gerar o ciclo empresarial onde figuram (Marques, 2015). Numa primeira etapa está o setor base do agronegócio, traduzido pelas indústrias e pelo varejo de

\footnotetext{
${ }^{5}$ Desde 1938, as estatísticas agropecuárias, até então executadas sob a responsabilidade do Ministério da Agricultura, passaram a ser realizadas pelo IBGE, que sistematizou seus resultados, antes obtidos por métodos variados, apresentando os principais aspectos das pesquisas agropecuárias contínuas atualmente realizadas pelo Instituto, contemplando os seguintes eixos temáticos: Produção vegetal (Levantamento Sistemático da Produção Agrícola - LSPA, Produção Agrícola Municipal - PAM e Produção da Extração Vegetal e da Silvicultura - PEVS); Produção animal (Pesquisa da Pecuária Municipal - PPM, Produção de Ovos de Galinha - POG, Pesquisa Trimestral do Abate de Animais, Pesquisa Trimestral do Leite e Pesquisa Trimestral do Couro); e Estoque (Pesquisa de Estoques).
} 
insumos, em fase de pré-produção rural (vendas de sementes, fertilizantes, defensivos químicos, equipamentos, publicidade, maquinário, representantes comerciais, etc.). Em seguida estão os empresários donos dos negócios agropecuários propriamente ditos, as pessoas jurídicas pertencentes aos produtores rurais, de variados portes em área rural (Borges, 2012).

$\mathrm{O}$ ciclo é encerrado pelas empresas de beneficiamento e distribuição dos bens produzidos, levando para a comercialização os produtos agropecuários até o consumidor (cooperativas de leite, frigoríficos, indústrias têxteis, caminhoneiros, distribuidores de alimentos, transportadoras marítimas, etc.). Durante o ciclo de produção, é imprescindível a parametrização das relações através da pactuação contratual entre as partes, pois o campo produz não somente os doces frutos da agricultura e da pecuária, mas também aqueles amargos, plantados e cultivados junto às relações humanas, formando a essência dos conflitos (Marques, 2015).

\section{Preços em Agronegócio e a Base Contratual}

Os números do agronegócio no Brasil correspondem a 23\% do PIB brasileiro, cuja receita aproximada é de $\mathrm{R} \$ 1,3$ trilhões de reais (IBGE, 2017), e em muito tem contribuído para mitigar os graves efeitos da recessão. O Ministério da Agricultura, Pecuária e Abastecimento, em 2018, apontou que o Agronegócio movimentou 23,5\% do Produto Interno Bruto brasileiro, subdistribuídos conforme apresentado a seguir:

Figura 1. Participação do Agronegócio no PIB do Brasil, em 2018.

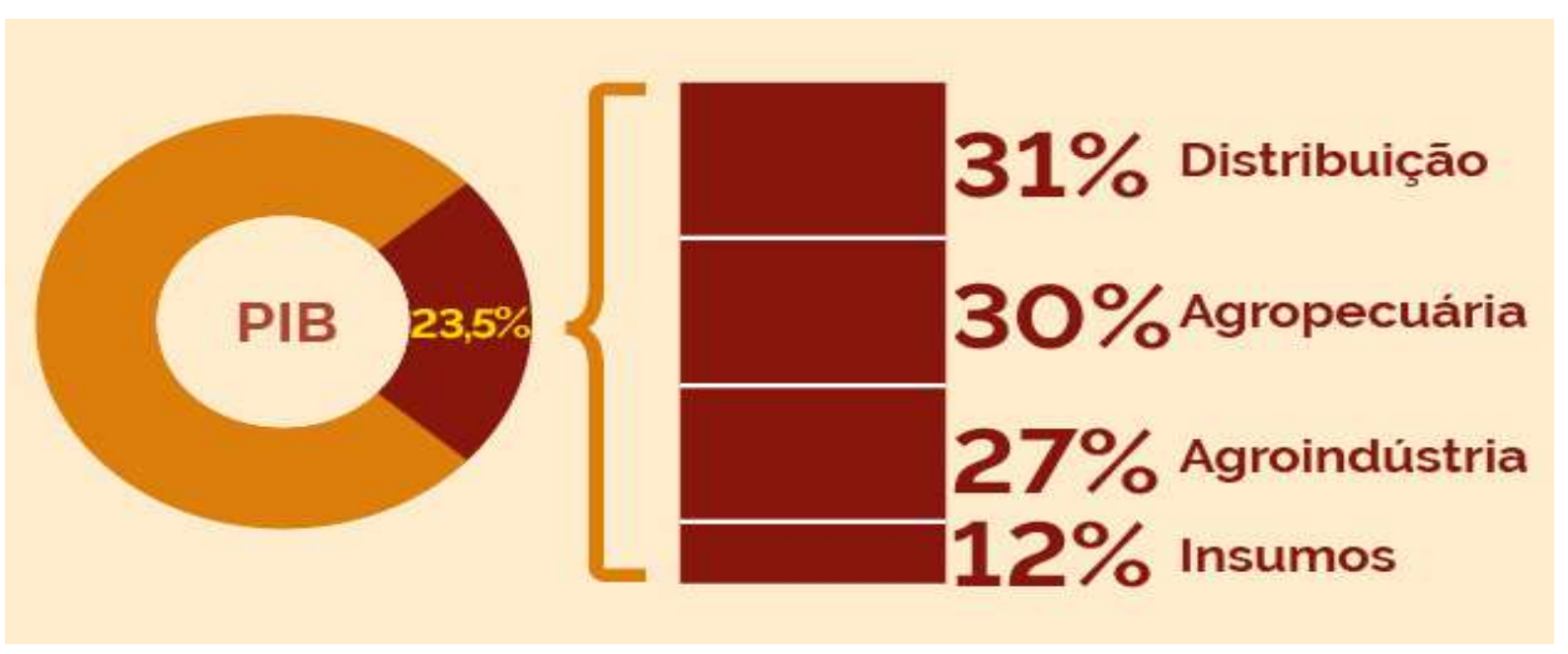

Fonte: Recuperado de AGROSTAT - Estatísticas de Comércio Exterior do Agronegócio Brasileiro. MAPA (2018).

Dos resultados preliminares do Brasil referente ao Censo Agro 20176, que cuida da Produção, colhem-se os seguintes indicativos: (i) 1,6 milhão de estabelecimentos agropecuários que cultivam o milho em grão, com produção de 91 milhões de toneladas; (ii) 104 milhões de toneladas de soja produzida em grão em mais de 236 mil estabelecimentos agropecuários; (iii) 172 milhões de cabeças de gado correspondem ao efetivo de bovinos; (iv) 30 bilhões de litros de leite de vaca, sendo que a produção de queijo e requeijão perfazem 316 mil toneladas; (v) 1,45 bilhão de cabeças de aves (galináceos), tendo a produção de ovos atingido 4,7 bilhões de dúzias; (vi) 7,2 bilhões é o número de pés de cafés existentes nos estabelecimentos agropecuários, onde em cerca de 265 mil estabelecimentos agropecuários foram produzidas 2 milhões de toneladas de café arábica; 520 mil toneladas de café canephora. Além disto, a produção de café torrado foi de 47,7 mil toneladas, sendo 35,4 mil em grão e 12,3 mil moído. (IBGE, 2017). Nesse sentido:

${ }^{6}$ O Censo Agropecuário teve a coleta de dados executada de outubro de 2017 a fevereiro de 2018, adotando-se como referência o período de $1^{\circ}$ de outubro de 2016 a 30 de setembro de 2017, relacionado os dados sobre a propriedade, produção, área, pessoal ocupado, etc. 
Já na seção do Censo Agro 2017, sobre os Estabelecimentos e produtores, ao tratar especificamente sobre os estabelecimentos, extraem-se os seguintes indicativos: (i) cerca de 70\% dos estabelecimentos tem área entre 1 e 50 hectares, sendo que dentre aqueles que possuem a maior concentração por grupo de área, dentre os 03 primeiros estão os de 1 a 10 ha, por perfazer $38,2 \%$ dos estabelecimentos; seguidos dos grupos de 10 a 50 ha com $31,3 \%$ e os que tem menos de 1 ha com $12 \%$ dos estabelecimentos; (ii) a área de todos os estabelecimentos agropecuários é de 350 milhões de ha, tendo sido registrado um aumento de 5\% em relação ao último censo de 2006; (iii) quanto à condição legal das terras tem-se que 86\% ou 301 milhões de ha são de terras próprias; (iv) a utilização da terra é voltada para lavouras permanentes $(2,4 \%)$ e temporárias $(16,5 \%)$; pastagens naturais $(13,9 \%)$ e plantadas $(33,2)$; matas naturais $(31,5 \%)$ e plantadas $(2,5 \%)$. Do mesmo relatório, sobre os produtores tem-se os seguintes dados: (i) quanto ao sexo estão divididos em 18,7\% feminino e 81,3\% masculino; (ii) quanto à idade, aqueles que possuem entre 30 e menos de 60 anos correspondem a 60,2\% da população, enquanto do que possuem 60 ou mais são 34,3\% ficando os menores de 30 anos com a parcela de 5,5\%; (iii) os que são alfabetizados correspondem a 77,0\% dos produtores enquanto dos que não são alfabetizados integram os 23,0\% restantes; (iv) o número de pessoas ocupadas em atividades agropecuárias perfaz 15 milhões. Destacando-se que em relação ao último censo (2006) tem-se uma diminuição de 9,2\%. (IBGE, 2017).

Na comparação, o quinquênio subsequente, observado entre janeiro de 2017 a janeiro de 2021, apresentou aumentos das exportações, com exceção de 2019, em bilhões de dólares, conforme as informações abaixo:

Figura 2. Índice de evolução das exportações no agronegócio.

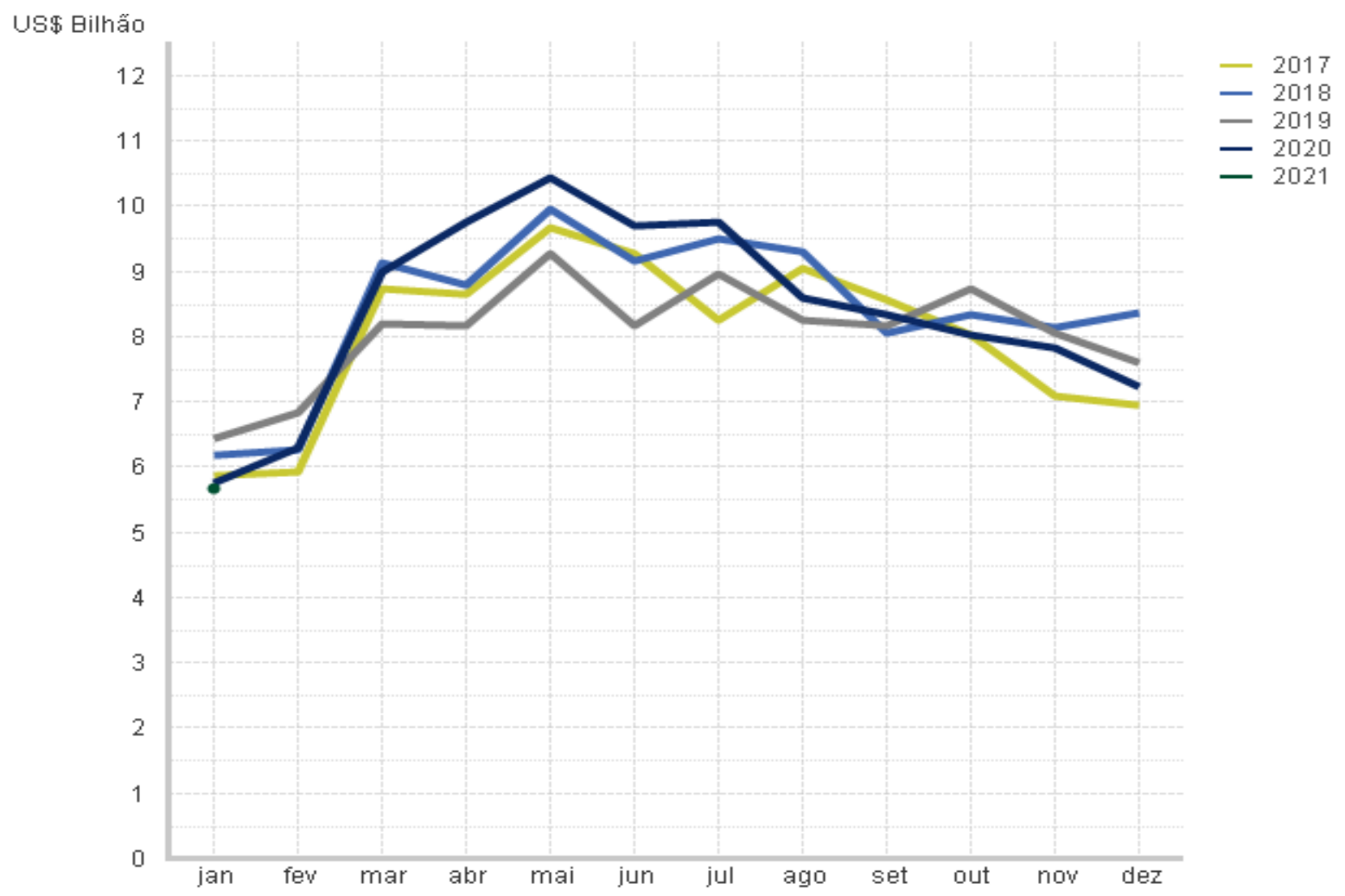

Fonte: Recuperado de AGROSTAT - Estatísticas de Comércio Exterior do Agronegócio Brasileiro. MAPA (20210.

A sofisticação dos negócios empreendidos no campo, com o emprego massificado de tecnologias também reformulou o modo como os litígios que deles se originam podem ser resolvidos, pois se tornaram geometricamente mais complexos, exigindo soluções mais rápidas e eficazes que nem sempre são encontradas junto ao Poder Judiciário. São portanto mais adequados para essas situações os métodos extrajudiciais de resolução de conflitos, como a mediação empresarial e arbitragem. 


\subsection{Contratos e conflitos}

Com as Leis n 9.307, da arbitragem (Brasil, 1976), e a Lei no 13.140, da mediação (Brasil, 2015), os litígios relativos a direitos patrimoniais disponíveis podem ser resolvidos de maneira facilitada, sempre buscando a solução harmônica de conflitos. Desta forma, uma série de contratos peculiares ao agronegócio pode ser observada como fontes de demandas passíveis de solução, sendo que diante da gama de possibilidades contratuais relativas ao agronegócio, pode-se citar os de: (i) compra e venda de sementes, defensivos e insumos; (ii) de produção para a criação de gado; (iii) de empréstimo; (iv) seguro agrícola; (v) financiamento rural; (vi) condomínios rurais; (vii) em contratos agrários de parceria e arrendamento; (viii) contratos socais e acordos de acionistas ou joint ventures, entre outros.

Alinhado ao modelo contratual voltado para o agronegócio, que por si só pode dar ensejo ao conflito, está a essência da relação, o objeto para o qual se volta a discussão, haja vista que os contratos agrícolas são particularmente propensos a serem afetados por fatores externos que podem impedir as partes de cumprir suas obrigações contratuais. Eventos externos que podem afetar os contratos são principalmente eventos naturais (secas, inundações, pragas e assim por diante), mas também podem estar relacionados a decisões governamentais, por exemplo, mudanças na política governamental em relação à agricultura. Além disso, a probabilidade de ocorrência de eventos externos afetando o contrato é reforçada pelo fato de os contratos agrícolas terem duração a médio ou longo prazo e pelo fato de que as partes assumem obrigações diferidas. As obrigações das partes às vezes estão inter-relacionadas e a capacidade de uma parte para executar depende do cumprimento prévio pela outra parte.

Dentre as questões judicializadas que tem como pano de fundo o agronegócio, cabe destacar as demandas: (i) ambientais; (ii) de fornecimento e de integração vertical; (iii) que cuidam do direito de superfície e constituição de usufruto; (iv) acerca de divisões de terras; (v) de dissolução de condomínios rurais; (vi) de servidões; (vii) sobre relações societárias decorrentes de estatutos. Entretanto, o preço do contrato é o grande objeto de discussão, pois fundamentado na boa-fé como cláusula geral e respaldado por inúmeros institutos do Direito Contratual, do Consumidor, Econômico e Civil, enseja conflitos cujos contornos são peculiares às relações por ele balizadas. Na perspectiva de Keynes, "o nível de preços como um todo é determinado precisamente da mesma maneira como os preços individuais, isto é, sob a influência da oferta e da demanda, face aos juros, taxas cambiais, impostos e gastos com mão de obra (Keynes, 1996, p. 40).

As mediações e as arbitragens em agronegócios, advindas de discussões quanto a preços em contratos, têm o condão de modular o pragmatismo da norma, quando assume feições próprias e precisa se adequar à realidade das partes, no intuito de produzir uma conciliação, ou uma resposta à demanda, de maneira satisfatória. Segundo Habermas, na obra Direito e democracia "a vontade política de uma comunidade jurídica, que também deve estar em harmonia com ideias morais, é a expressão de uma forma de vida compartilhada intersubjetivamente, de situações de interesses dados e de fins pragmaticamente escolhidos" (Habermas, 1997, p. 194).

Disso é possível concluir que os conflitos em contratos resolvidos mediante os mecanismos de mediação e arbitragem devem obedecer às normas do direito e, necessariamente, devem estar de acordo com normas morais, expressando em fins pragmáticos, a referência a questões de segurança jurídica em consonância aos estilos de vida e modelos de negócios adotados pelas partes contratantes, dando uma solução mais personalizada à formação dos contratos, até o seu adimplemento total, ou reajuste de preços, via conciliação.

\subsection{Contratos globalizados: mediação e arbitragem internacionais}

A economia globalizada permitiu que empresas transnacionais expandissem seus empreendimentos em agronegócios no Brasil. Logo, a utilização de contratos mesclando direitos internacionais privados (DIPr) se tornou uma constante neste 
ramo da economia. Neste sentido, a mediação e a arbitragem têm ganhado ainda mais espaço, como via para acordos entre partes, evitando complexos processos entre países com legislações exponencialmente contrastantes.

A arbitragem, neste prisma, é um meio de solução de controvérsias bastante difundido na maioria dos países ocidentais e, sendo assim, pode ser considerada como um mecanismo de diálogo comum entre partes, pois seus paradigmas são de bastante similares (Timm, 2009, p. 27). Além disso, atua internacionalmente de modo eficaz, evitando que as discussões judicializadas imponham à parte vencida sanções de cunho judicial a empresários, que impliquem total perda de saúde econômica, tal como multas extraordinárias e recuperação judicial, dentre outros.

As estruturas das relações interestatais ou internacionais do mercado mundial não encontram consonância com o Estado, pois as esferas de atuação deste possuem limites menores do que os dos mercados em si. Estes limites compreendem a economia, a política, as questões migratórias, as guerras, os meios de comunicação, a conquista de territórios espaciais, o desenvolvimento sustentável, em áreas onde o Estado tem perdido em autonomia; em competência para a ação e em substância democrática (Habermas, 2003, p. 106).

A mediação e a arbitragem podem ser realizadas com o apoio de agentes privados, ou instituições internacionais, que possuem câmaras especializadas em matérias vinculadas a agronegócios. As principais são: Recursos de Arbitragem Comercial Internacional (Escola de Direito da Universidade de Chicago), Câmara de Comércio Internacional: Comissão de Arbitragem, Conselho Internacional de Arbitragem Comercial, Tribunal de Londres de Arbitragem Internacional, Tribunal Permanente de Arbitragem, Comissão das Nações Unidas sobre Direito do Comércio Internacional, Associação Nacional de Mediação Comunitária, ADR do Canadá, Lei de Mediação da Dívida da Fazenda do Canadá, Centro de Arbitragem e Mediação da Organização Mundial da Propriedade Intelectual. Assim, qualquer conflito multilateral e internacional poderá ser apoiado por tais entidades.

\section{Interpretação Doutrinária}

Os contratos agrários surgiram diante da necessidade de regulamentação das relações de uso ou posse temporária do imóvel rural. Sua definição é encontrada em Borges (2012, p. 465) como sendo o "acordo de vontades entre o proprietário ou possuidor do imóvel rural com aquele que pretende temporariamente trabalhar a terra em atividades agrícolas e pastoris, mediante o pagamento de uma renda ou frutos", enquanto Edson Ferreira de Carvalho (2010, p. 394) o conceitua a "grosso modo, como acordos de vontade, firmados segundo as leis 4.504/1964 (arts. 92 a 96) e 4.947/1966 (arts. 13 a 15) e Decreto 59.566/1966, com a finalidade de resguardar, modificar ou extinguir direitos relativos à exploração do imóvel agrário ou parte dele. Entretanto, destaca-se que a Lei de Terras (1850) foi omissa quanto ao resguardo das relações jurídicas contratuais atinentes às atividades agrárias, vindo tal matéria ser introduzida no ordenamento jurídico pátrio somente no Código Civil de 1916 (artigos 1.211 a 1215 e 1.410 a 1.423), com previsões especiais aplicadas aos prédios rústicos. Estabeleceu-se, aí, previsões referentes à parceria agrícola e ao arrendamento rural, com forte incidência da primazia da liberdade individual, num contexto de paridade de igualdade entre proprietários e parceiros ou arrendatários.

Com o advento do Estatuto da Terra, a Lei $\mathrm{n}^{\circ} 4.504$ (Brasil, 1964), os contratos agrários passaram a possuir regulamentação própria e nesta nova roupagem legal a mudança de paradigma restou estabelecida diante do afastamento da paridade de igualdade dos atores envolvidos na relação. Isso porque, o Estatuto da Terra subtraiu das partes o que o diploma anterior tinha de mais peculiar em matéria contratual: a total liberdade de contratar. A vontade das partes cedeu espaço para o que restou convencionado chamar de "dirigismo contratual" (Carvalho, 2010, p. 394). A partir de então, aos contratos agrários são estabelecidas limitações à vontade das partes, sendo que a justificativa para tanto é respaldada na proteção da parte mais fraca da relação contratual e na garantia da efetividade da utilização do imóvel rural tendo como parâmetro a produtividade e a sustentabilidade. 
Tratando especificamente do objeto a que se desdobra os estudos em questão, tem-se o contrato de parceria rural previsto Decreto 59.566/66, sendo seu conceito disposto no artigo $4^{\circ}$ nos seguintes termos:

Art. $4^{\circ}$. Parceria rural é o contrato agrário pelo qual uma pessoa se obriga a ceder à outra, por tempo determinado ou não, o uso específico de imóvel rural, de parte ou partes do mesmo, incluindo, ou não, benfeitorias, outros bens e ou facilidades, com o objetivo de nele ser exercida atividade de exploração agrícola, pecuária, agroindustrial, extrativa vegetal ou mista; ou lhe entregue animais para cria, recria, invernagem, engorda ou extração de matérias-primas de origem animal, mediante partilha de riscos de caso fortuito e da força maior do empreendimento rural, e dos frutos, produtos ou lucros havidos nas proporções que estipularem, observados os limites percentuais da lei. (Brasil, 1966, on-line)

Das características que naturalizam o contrato de parceria rural tem-se a pessoa que cede à outra o uso específico de determinado imóvel rural, tendo como objetivo o exercício de exploração agrícola mediante partilha dos riscos, do caso fortuito e da força maior da atividade a que se volta o empreendimento rural, bem como dos frutos, produtos ou lucros havidos nas proporções estipuladas pelas partes.

Assim é que ao existir previsão contratual que destine parcela da produção como contraprestação devida ao proprietário, se estará diante de contrato de parceria agrícola. Efetuada a contratação sob denominação diversa de contrato de parceria agrícola, mas tendo prevalecido a álea, esta serve como mecanismo capaz de afastar os elementos fixados no contrato. Nesse sentido, a partilha dos riscos surge como elemento intrínseco para que se proceda à estipulação dos preços daquilo que corresponde ao lucro ou à produção agrícola, não havendo que se falar em limites às estipulações de entrega de parte da safra ou dos frutos.

No intuito de esclarecer as diferenças existentes diante das vantagens e riscos entre o contrato de parceria de arredamento agrícola, cumpre trazer à tona as lições de Benedito Ferreira Marques (2005, p. 231), para quem:

[..] no arrendamento, as vantagens e os riscos são do arrendatário, ficando o arrendador com o direito de receber o aluguel, sem nenhum risco de frustração do empreendimento; já na parceria, os riscos e as vantagens são de ambas as partes, já que os resultados são partilhados, lucros ou prejuízos.

Ultrapassada a questão conceitual acerca do contrato de parceria agrícola e da formulação de suas características, impõem-se o enfrentamento da questão pendente de pacificação doutrinária, cujo objeto é o preço do contrato agrário de parceria, sendo o cerne do impasse encontrado na validade da autonomia da vontade diante da estipulação do preço do contrato frente aos limites previstos pelo ordenamento jurídico.

No contrato de parceria agrícola, os percentuais de participação do proprietário nos frutos são elencados o artigo 96, IV do Estatuto da Terra, conforme alteração trazida pela Lei nº 11.443/2007, nos seguintes termos:

Art. 96. Na parceria agrícola, pecuária, agroindustrial e extrativa, observar-se-ão os seguintes princípios:

$[\ldots]$

VI - na participação dos frutos da parceria, a quota do proprietário não poderá ser superior a:

a) $20 \%$ (vinte por cento), quando concorrer apenas com a terra nua;

b) $25 \%$ (vinte e cinco por cento), quando concorrer com a terra preparada;

c) $30 \%$ (trinta por cento), quando concorrer com a terra preparada e moradia;

d) $40 \%$ (quarenta por cento), caso concorra com o conjunto básico de benfeitorias, constituído especialmente de casa de moradia, galpões, banheiro para gado, cercas, valas ou currais, conforme o caso;

e) 50\% (cinquenta por cento), caso concorra com a terra preparada e o conjunto básico de benfeitorias enumeradas na alínea d deste inciso e mais o fornecimento de máquinas e implementos agrícolas, para atender aos tratos culturais, bem como as sementes e animais de tração, e, no caso de parceria pecuária, com animais de cria em proporção superior a 50\% (cinquenta por cento) do número total de cabeças objeto de parceria; 
f) $75 \%$ (setenta e cinco por cento), nas zonas de pecuária ultra extensiva em que forem os animais de cria em proporção superior a $25 \%$ (vinte e cinco por cento) do rebanho e onde se adotarem a meação do leite e a comissão mínima de $5 \%$ (cinco por cento) por animal vendido;

g) nos casos não previstos nas alíneas anteriores, a quota adicional do proprietário será fixada com base em percentagem máxima de dez por cento do valor das benfeitorias ou dos bens postos à disposição do parceiro. (Brasil, 1964).

A extensa gama de críticas e de posicionamentos contraditórios entre si acerca do tema em análise se perfaz já nos estudos que se voltaram para os projetos que culminaram na alteração efetuada pela Lei 11.443/2007 ao Estatuto da Terra, o que nos dizeres de Alencar Proença é visto da seguinte forma:

Examinei, tão minuciosamente quanto possível, os dois Projetos de Lei que lhe deram origem. Li e reli o trabalho do Relator de ambos os projetos e não encontrei um argumento, sequer, razoavelmente aceitável, em especial para a expressiva alteração dos percentuais de participação dos proprietários nas avenças de parcerias. Surpreendi-me, mais ainda, com a pacífica aprovação do Poder Executivo aos novos percentuais, posto que, indubitavelmente, são benefícios concentradores de renda nas mãos dos proprietários, retirando importantes recursos da atividade rural. (Proença, 2007, p. 192)

De forma mais detida, ao tratar do artigo acima mencionado tem-se que a previsão legal não deixa clara a questão de o rol e seus percentuais devam ser aplicados de forma taxativa ou se trata de questões exemplificativas, menos ainda se tais parâmetros possam ser negociáveis quando inseridos em produções temporárias e passa mais distante ainda da avaliação acerca da ausência de necessidade de proteção da parte hipossuficiente quando dentro da relação contratual é difícil aferir quem a caracterize.

Há quem entenda ser a enumeração apenas exemplificativa, o que garante às partes autonomia quanto às benfeitorias e benefícios, sendo tal posicionamento defendido por Silvia Opitz e Oswaldo Opitz (2016).

É de se destacar que parte da doutrina firmada por Cassetari (2012), Marques (2015) Proença (2007), Coelho (2011) e Borges (2007) não se manifestou sobre a possibilidade de inaplicabilidade ou alterações dos percentuais despendidos no artigo acima mencionado, tampouco quanto à validade dos rearranjos feitos pelas partes quando voltadas para atividade-fim diversa da prevista nos termos da lei. A omissão encampada pelos doutrinadores aqui citados é encerrada diante do reconhecimento da possibilidade de majoração em até $10 \%$ no caso de benfeitorias e bens colocados à disposição do parceiro outorgado, nos exatos termos do que prevê o Estatuto da Terra, no artigo 96, VI, "g" e no inciso IX do mesmo artigo.

De outro lado, está Antonino Moura Borges (2012) para quem os percentuais estabelecidos no Estatuto da Terra referem-se a culturas temporárias, devendo, pois as culturas permanentes serem fixadas sob outros critérios diante da dificuldade de se encontrar um parâmetro absoluto, fixo, exato, o que abre espaço para a autonomia das partes para tais ajustes. Pontua, ainda, que os ajustes devam ser justificados, sob pena de serem considerados ineficazes, bem como há a necessidade de indicação precisa acerca do fornecimento de utensílios e benfeitorias que poderão ser compensados, de tal modo que se tem por permitida a fixação de percentuais de pagamento diversa da prevista em lei, desde que resguardado percentual que não seja superior a $10 \%$ do valor das benfeitorias ou bens entregues ao parceiro agricultor.

Se por um lado a questão do preço é em várias vertentes contraditórias diante da doutrina, no que se referem ao pagamento no contrato de parceria as contradições são mais amenas. Isso porque, da previsão legal não emerge qualquer óbice ou discriminação do que possa ser entendido como pagamento da parceria, cabendo tão somente ao Estatuto da Terra tal disposição, no artigo 96, II, integrando a ele as normas do "arrendamento rural, no que couber, bem como as regras do contrato de sociedade, no que não estiver regulado pela presente Lei.” (Brasil, 1964). Deste modo, as mesmas regras de conversão de frutos em dinheiro previstas no contrato de arrendamento, mostram-se perfeitamente aplicáveis ao contrato de parceria em que o preço é estipulado em frutos. 
Ademais disto, registra-se que a antecipação do valor estabelecido é possível, assim como o é a estipulação prévia entre as partes acerca do volume ou quantidade equivalente ao seu percentual na parceria, sendo cabível o reajuste do valor acordado em conformidade com a produção, que só será aferida em momento posterior. Tais previsões encontram-se dispostas no artigo 96 do Estatuto da Terra, nas modificações que a ele foram inseridos os $\S \S 2^{\circ}$ e $3^{\circ}$.

Tendo em vista o silêncio do Estatuto da Terra quanto à forma de ajuste quando o valor pago exceda ao correspondente à produção ou ao lucro, a doutrina tem se inclinado à adoção do entendimento perfilado diante do contrato de arrendamento com preço em frutos, com a da possibilidade do recebimento antecipado, como ocorre nos casos de venda de safra futura pelo parceiro-outorgado. Este mesmo posicionamento tem sido adotado por muitos tribunais pátrios.

\section{Interpretação Jurisprudencial}

Para a compreensão da temática aqui desenvolvida diante dos tribunais estaduais, a análise jurisprudencial enfrentada comporta a pesquisa realizada nos sítios eletrônicos dos Tribunais Estaduais de Goiás, Minas Gerais e São Paulo. A escolha destes tribunais estaduais, deve-se ao fato de serem os estados pesquisados aqueles em que o agronegócio possui acentuado desenvolvimento sob várias perspectivas de plantação, criação, tecnologia empregada, etc., o que favorece o enfrentamento de culturas do agronegócio diversificadas pelos tribunais.

Os parâmetros lançados na realização da pesquisa jurisprudencial têm limitação temporal que se estende até 2009, sendo que os critérios de busca dos indexadores foram estabelecidos pelas palavras "frutos" e "parceria". Assim, na pesquisa jurisprudencial realizada no sítio eletrônico do Tribunal de Justiça de Goiás, dos 13 acórdãos que apresentaram a incidência das palavras indexadas, 03 fundamentavam o preço/pagamento do contrato de parceria rural nos moldes estabelecidos nos contratos firmados entre as partes, enquanto quatro destes acórdãos as decisões utilizavam como parâmetro os mesmos estabelecidos pelo Estatuto da Terra. Os demais acórdãos tratavam de questões diversas ao objeto deste trabalho e, por isso, não foram computados nesta pesquisa.

Já no Tribunal de Justiça de Minas Gerais, das 23 decisões encontradas, tinha-se em sete destes acórdãos a análise do objeto deste estudo. Verificados os argumentos jurídicos expostos em cada um dos acórdãos válidos ao fim que se presta este estudo, pode-se constatar em três deles o parâmetro desenhado na decisão seguiu as previsões legais do Estatuto da Terra, em especial, a que cuida dos percentuais do preço estabelecido no contrato, quando este parâmetro não existia ou quando o percentual era diverso do apontado na lei. Por outro lado, os outros 04 acórdãos analisados entendiam pela força do contrato firmado entre as partes, destacando-se para tanto a autonomia da vontade com a sua inserção nas questões fáticas, numa análise casuística em que até a previsão anual escalonada com a majoração do percentual de pagamento do preço do contrato veio a ser aceita.

Por fim, quanto ao Tribunal de Justiça de São Paulo, dos 76 acórdãos encontrados, 10 se desdobravam sobre o tema em análise, sendo que 04 baseavam-se nas questões contratuais e os outros 06 se valiam de fundamentação diante da autonomia contratual. As razões trazidas nas decisões objetos deste estudo não traziam um enfrentamento claro e preciso acerca do afastamento do Estatuto da Terra para se privilegiar a autonomia das partes dentro da relação contratual. De maneira bem objetiva, diante das cláusulas contratuais estabelecidas pelas próprias partes, tinha-se traçado os limites do julgamento e da atuação judicial, exceto, quando necessária a liquidação dos frutos (em especial, diante de casos em que o preço/pagamento fora fixado no peso da criação e quando o contrato veio a se estender no tempo, ultrapassando a esfera expressa e vindo a se prolongar de forma tácita, mas diante de outra geração da família).

Nesse cenário, em que parte da doutrina ao tratar do preço dos contratos agropecuários de parceria, assenta seus argumentos em possibilidades dentro de um mercado que não se mostra construído, eis que dinâmico, complexo e não estático, que pode vir a sofrer influências de pressão, temperatura, pragas, desastres, etc. de esfera local, nacional e internacional para 
fundamentar a necessidade de uma flexibilização de conceitos e previsões legais, enquanto a outra parte da doutrina se vale dos mesmos argumentos para tornar impositiva a previsão legal, tem-se por formado um campo de discussão em que a análise casuística dos termos e limites do contrato começam a configurar a celeuma judicial.

$\mathrm{O}$ judiciário frente às questões que ultrapassam os limites dos conhecimentos que circundam as máximas de experiência do julgador, necessita de elementos que venham a fundamentar uma decisão que ao ser entregue aos litigantes encontre elementos que a justifique, ao mesmo tempo em que reste garantida a segurança jurídica. Ocorre que, em casos como o em análise, em que a doutrina é marcantemente divergente, a análise das questões fáticas que conduzem ao entendimento a ser proferido pelo juízo fica sujeita à escolha da tese que encontrar maior correspondência com aquilo que ecoa como sinônimo de melhor entrega decisória de efetivação dos sustentáculos da justiça.

Fosse essa a única e exclusiva questão insólita a ser enfrentada diante do tema aqui apresentado, a solução poderia vir da escolha da doutrina majoritária; todavia, a jurisprudência aplicável ao caso também tem se mostrado vacilante, o que acaba por gerir e fomentar as discussões em um campo de aplicação onde a demora de uma solução eficaz e correta se transmuta em prejuízos das mais variadas espécies e proporções.

A ausência de elementos que possam convergir em entendimentos doutrinários e jurisprudenciais mostra-se fundamental para o enriquecimento do debate, mas a ausência de um enfrentamento baseado na oportunidade de os circunscritos travarem diálogos em que seja oportunizada a apresentação dos seus pontos de vistas; das consequências advindas de cada tipo de caminho a ser trilhado por uma decisão horizontalizada são assaz prejudiciais àqueles que se encontram inseridos no conflito.

As polarizações das partes e de seus fundamentos constituem óbices para a construção de um entendimento que, voltado para a análise dos múltiplos fatores (econômicos, políticos, sociais, contratuais, etc.) em que os circunscritos estão envolvidos, acaba não por pacificar o conflito, mas por amenizá-lo, já que a decisão advinda de forma verticalizada em tempo muito diverso da efetiva ocorrência dos fatos , não comporta em si todos os efeitos de uma solução, pois pode ocorrer de o percurso entre a ocorrência do liame e a sua análise judicial terem tantos outros danos e reflexos deles provenientes, que a decisão imposta compreenda apenas os efeitos de um paliativo aos malefícios dos desdobramentos processuais.

Ao se entregar ao Estado o poder de decidir de forma impositiva os conflitos em que os atores processuais se encontram inseridos acaba por se afastar a congregação dos interesses e a integração social de construção de uma solução alinhada aos limites, responsabilidades e previsões de atuação, ora sob os viesses das concepções republicanas frente às liberais ou vice-versa, ora sob a interferência de questões de ordem políticas; econômica; religiosa; cultural; social; estatística; dentre outras.

A congregação dos valores referentes às posturas adotadas pelos atores processuais ao passarem pelo filtro das deliberações devem ter como finalidade o restabelecimento do equilíbrio dos interesses. Todo esse procedimento não deve se desenvolver levando-se em conta somente as formas de arranjos de interesses tampouco sob a forma de uma ética válida para uma comunidade; mas sim sob "regras discursivas e formas argumentativas que extraem seu teor normativo da base validadora da ação que se orienta ao estabelecimento de um acordo mútuo, isto é, da estrutura da comunicação linguística" (Habermas, 2012, p. 278).

\section{Eficácia nas Resoluções de Conflitos}

A denominada "cultura da sentença" que decorre da valorização excessiva da solução dos conflitos de vertente impositiva, verticalizada, apesar de ainda encontrar grande área de atuação, tem cedido espaço aos meios alternativos, em especial aos métodos da mediação e da arbitragem. 
Até então os meios alternativos de resolução das controvérsias tem tido a sua mola propulsora em justificativa que se funda na solução para a morosidade do judiciário, como meio de redução do congestionamento de processos a serem julgados, o que não corresponde à leitura correta daquilo a que se presta a conciliação, a mediação e a arbitragem. A bem da verdade, os meios alternativos de resolução de controvérsias devem ser vistos sob o enfoque do tratamento adequado dos conflitos de interesse, já que as decisões indicadas, construídas ou proferidas dentro destes procedimentos emanam de uma visão mais integrada e particular do conflito, o que reveste de maior e melhor eficácia e eficiência, além de serem entregues em espaço de tempo mais célere.

Daí é que a negociação ganha destaque, sendo que por negociação deve-se entender como um "processo pelo qual duas ou mais pessoas se comunicam buscando chegar a algum acordo sobre valores escassos e/ou ações controladas, total ou parcialmente, por ambas as partes, ou ainda, por qualquer das partes envolvidas." (Burbridge et al., 2007, p. 9). A negociação pode tomar contornos de integrativa ou distributiva, sendo que uma não exclui a outra, mas podem ser visualizadas como fases de um procedimento de negociação em que cada uma dessas fases possui características peculiares e denotam habilidades e técnicas específicas. Há casos, no entanto, em que há a prevalência dos interesses opostos, sem que se consiga identificar elementos ou interesses, comuns ou diferentes, o que torna prejudicial a fase integrativa ao mesmo tempo em que é dado maior destaque para a fase distributiva. A questão então se volta para o seguinte horizonte: como negociar?

Segundo Margaret Neale e Max Bazerman (1992), na fase distributiva da negociação questões práticas acabam por corporificar o que se entende por "três preços" definidos em: (i) preço alvo: tido como desejável, aquele que se pretende alcançar; (ii) preço limite ou reserva: aquele projetado como negociável; até onde a margem de negociação pode atuar e (iii) preço âncora: é o valor trazido na primeira proposta da transação, sendo que ao valor lançado ainda existe um campo de atuação que dá margem às negociações. Assim é que fixados os preços alvo e limite pelo negociador, torna-se interessante analisar os mesmos critérios para aqueles com quem vai se negociar, para que o preço âncora atue numa área mais concentrada em que os riscos já tenham sido calculados e que permitam a concretização do acordo. A essa região onde o acordo é possível chama-se ZOPA (Zona de Possíveis Acordos).

O conhecimento da ZOPA dá ao negociador substancial vantagem estratégica, já que lhe confere condições de fazer a proposta inicial (Preço Âncora) que tenda a maximizar seus interesses e a acomodar minimamente os interesses do outro, até o limite aonde o outro lado esteja disposto a chegar ou ceder para fechar o acordo.

Diante dessa constatação, pode-se concluir que quanto mais preparado para a negociação e quanto mais informações o negociador tiver, melhores condições ele terá para identificar a ZOPA. (Mourão, 2014, p. 127)

Destaca-se aqui que as análises aritméticas por si só não criam terreno fértil para a negociação. Alinhada às análises fundadas em cálculos, devem ser consideradas ou estar sopesadas as questões emocionais e psicológicas dos envolvidos; as condições sociais das mais variadas ordens voltadas para o ambiente e para as pessoas, além das questões culturais regionais e internacionais. Voltada para a análise das pessoas envolvidas na negociação é de se ponderar as expectativas, ambições, desejos, percepções da realidade, fatores que configuram as posições de cada um dos atores. A ausência de observação de uma ou do conjunto destas questões pode tornar inconciliável uma proposta financeira que aparentemente era atraente ou negociável. Ainda a essa relativização de fatos e valores, somam-se à mutabilidade dos fatores naturais e governamentais que na esfera da negociação atinente ao agronegócio devem ser respaldadas na arte da valoração relativa das coisas.

Nesse ensejo, cabe trazer à discussão que tanto o preço quanto o pagamento são questões que demandam análise doutrinária e jurisprudencial quando aplicável ao contrato de parceria, ao mesmo tempo em que a eles são dedicadas fases especiais da negociação, o que tornam as questões até aqui pontuadas objetos de estudo que mereça uma análise detida também sob os vieses dos preceitos constitucionais e deste complexo universo do agronegócio. 
A partir dos princípios e fundamentos constitucionais que orbitam a ordem econômica tem-se que a fixação dos preços não deve resultar de normas cogentes, de tal modo que não haja intromissão nos limites do preço no contrato de parceria, o que vai de encontro ao que preceitua o Estatuto da Terra.

No mesmo sentido, a limitação imposta ao preço dos contratos agrários vai na contramão de direção aos princípios da livre iniciativa e da livre concorrência, o que vem se agravando diante da dificuldade de se presumir e/ou identificar a vulnerabilidade dos atores contratuais, o que já foi observado, por Nilson Marques (1976), diante da parceria pecuária da seguinte forma:

[...] é impossível afirmar, de maneira genérica, qual a parte mais fraca [...] carecedora da proteção do direito na era democrática que vivemos [...]. Em verdade, a parceria pecuária, em nosso meio, é estabelecida entre o proprietário dos animais de um lado e o proprietário das pastagens, de outro. Qual o mais fraco? Impossível precisar (Marques, 1976)

Isso sem contar no objetivo da cooperação a ser alcançada pelas partes em que se assenta o contrato de parceria, que é flagrantemente afastado diante da limitação do preço, já que as partes não conseguem colaborar umas com as outras na obtenção daquilo que isoladamente não conseguiriam alcançar, seja referente a bens e/ou a serviços. Ao ferir de morte a cooperação, elemento essencial ao contrato de parceria agrícola, está ainda a solapar a função socioeconômica do contrato e é na função socioeconômica do contrato reside a sua utilidade em relação à obtenção dessa satisfação, que ocorre pela cooperação entre as partes (Borges, 2007).

Neste sentido, tais relações contratuais, dentre outras, ilustram a possibilidade de utilização dos mecanismos de mediação e arbitragem na busca pela resolução alternativa, fomentando o diálogo entre as partes, na esfera privada, ou extrajudicial, de modo a permitir o reequilíbrio econômico-financeiro ou a alteração da base objetiva do negócio jurídico; bem como acordos sobre a precificação em operações de fusão e aquisição; acordos sobre contratos de compra e venda de determinado insumo agrícola (cana-de-açúcar, por exemplo), entre diversas outras possíveis.

\section{Conclusão}

Algumas das características da relação contratual (desequilíbrio de poder, baixo valor de troca econômica, potencial para comportamento oportunista, e assim por diante) levantaram desafios ao fazer cumprir contratos ou resolver disputas entre as partes. Este artigo reviu as diferentes teorias aplicadas à execução de contratos no âmbito do agronegócio e também apontou os problemas que surgem do uso de tribunais nacionais como um mecanismo de resolução de disputas nesta estrutura, sugerindo, como uma solução para superar essas deficiências, o uso dos mecanismos de mediação e arbitragem.

Sem dúvida, à medida que os problemas que cercam o agronegócio adquirem maior complexidade e os sistemas de tribunais tornam-se mais apoiados sob uma quantidade crescente de litígios. A mediação e a arbitragem no campo dos agronegócios se tornarão cada vez mais predominantes como métodos de resolução de disputas.

Mas a mediação e a arbitragem, além da funcionalidade ou da eficiência econômica que possam gerar, devem ser compreendidas como instrumentos viabilizadores de oportunidades para o fortalecimento da cidadania e da esfera pública, já que permitem o envolvimento dos concernidos na discussão, deliberação, implementação das decisões e fiscalização dos resultados daquilo que foi objeto de cada um destes métodos. Por isso, tais elementos de resolução de conflitos são importantes mecanismos para o fortalecimento do estado democrático de direito.

Longe de esgotar o tema, a mediação e a arbitragem no agronegócio, também precisa analisar o impacto das flutuações cambiais, em especial o dólar, como valor-base para o preço de commodities. Apesar de os produtos do agronegócio serem produzidos em solo brasileiro, sua cotação em moeda pode alterar, em muito, o mercado interno, as bolsas de valores de mercado futuro e a própria resolução de conflitos de maneira não judicial. Assim, é necessário que trabalhos futuros abordem 
tal recorte temático, no escopo de aprofundar os entendimentos sobre o objeto de pesquisa e colaborar para a visibilidade e aplicabilidade, cada vez mais amplos, dos métodos alternativos de resolução de conflitos, como ferramentas democráticas e de formação da cidadania.

\section{Referências}

Alves, E. R. de A., Souza, G. da S. E., \& Marra, R. (2011). Êxodo e sua contribuição à urbanização de 1950 a 2010 . Revista Política Agrícola, Brasília, DF, 20(2), 80-88.

Bazerman, M. H. \& Neale, M. A. (1992). Negotiating Rationally. The Free Press.

Borges. A. M. (2012). Curso Completo de Direito Agrário - Doutrina - Prática - Jurisprudencia - Legislação. Editora Contemplar.

Borges, R. C. B. (2007). Reconstrução do conceito de contrato: do clássico ao atual. In: Hironaka, G. M. F. N.; Tartuce, F. (Org.). Direito contratual: temas atuais. Método, 2007. p. 19-40.

Brasil. Conselho Nacional de Justiça. (2017). Justiça em Números 2017: ano-base 2016/Conselho Nacional de Justiça. Anual. Brasília: CNJ. 188p.

Brasil. (1964). Lei $n^{o}$ 4.504, de 30 de novembro de 1964 - Dispõe sobre o Estatuto da Terra, e dá outras providências. < https://presrepublica.jusbrasil.com.br/legislacao/104451/estatuto-da-terra-lei-4504-64>.

Brasil. (1996). Lei $n^{\circ}$ 9.307, de 23 de setembro de 1996: Dispõe sobre a arbitragem. <http://www.planalto.gov.br/ccivil_03/Leis/L9307.htm>.

Brasil. (1996). Lei $n^{\circ} 11.443$, de 5 de janeiro de 2007. Dá nova redação aos arts. 95 e 96 da Lei no 4.504 , de 30 de novembro de 1964, que dispõe sobre o Estatuto da Terra. < http://www2.camara.leg.br/legin/fed/lei/2007/lei-11443-5-janeiro-2007-549029-norma-pl.html>.

Brasil. (2015). Lei $n^{o}$ 13.140, de 26 de junho de 2015: Dispõe sobre a mediação entre particulares como meio de solução de controvérsias e sobre a autocomposição de conflitos no âmbito da administração pública; altera a Lei no 9.469, de 10 de julho de 1997, e o Decreto no 70.235 , de 6 de março de 1972; e revoga o § 20 do art. 6o da Lei no 9.469, de 10 de julho de 1997. < http://www.planalto.gov.br/CCivil_03/_Ato2015-2018/2015/Lei/L13140.htm>.

Burbridge, R. M. (2007). Gestão de negociação. (2a ed.), Saraiva.

Cahali, F. J. (2012). Curso de Arbitragem. (2a ed.), Revista dos Tribunais.

Cassetari, C. (2012). Direito agrário. Atlas. 230 p.

Cretella Neto, J. (2004). Curso de Arbitragem: arbitragem comercial, arbitragem internacional, Lei brasileira de arbitragem, Instituições internacionais de arbitragem, Convenções internacionais sobre arbitragem. Forense.

Coelho, J. F. L. (2011). Contratos agrários: uma visão neoagrarista. Juruá Editora.

Habermas, J. (1997) Direito e democracia. Tempo brasileiro.

Habermas, J. (2002). A inclusão do outro - estudos de teoria política. Edições Loyola. 390 p.

Habermas, J. (2003) Era das transições. Trad. e intro. de Flávio Siebeneichler. Tempo brasileiro. 222 p.

Instituto Brasileiro De Geografia E Estatística - IBGE. (2018). Pesquisas agropecuárias: IBGE - Coordenação de Agropecuária. (3a ed.), IBGE.

Instituto Brasileiro De Geografia E Estatística - IBGE. (2017) Censo Agropecuário $2017 \quad$ - Resultados Preliminares. IBGE. <https://sidra.ibge.gov.br/pesquisa/censo-agropecuario/censo-agropecuario-2017>.

Keynes, J. M. (1996). A Teoria Geral do Emprego, do Juro e da Moeda. Trad. Mário R. da Cruz. Editora Atlas S.A. 352 p. < http://www.ie.ufrj.br/intranet/ie/userintranet/hpp/arquivos/090320170036_Keynes_TeoriaGeraldoempregodojuroedamoeda.pdf>.

Koche, J. C. (2011). Fundamentos de metodologia científica. Petrópolis: Vozes. http://www.brunovivas.com/wp-content/uploads/sites/10/2018 $/ 07 / \mathrm{K} \% \mathrm{C} 3 \%$ B6che-Jos\%C3\%A9-Carlos0D0AFundamentos-de-metodologia-cient\%C3\%ADfica-_teoria-da0D0Aci\%C3\%AAncia-e-inicia\%C3\% $\mathrm{A} 7 \% \mathrm{C} 3 \% \mathrm{~A} 30-\% \mathrm{C} 3 \% \mathrm{~A} 0$-pesquisa.pdf 5.2).

Ludke, M. \& Andre, M. E. D. A. (2013). Pesquisas em educação: uma abordagem qualitativa. E.P.U.

Marques, B. F. (2015). Direito agrário brasileiro. (11a ed.), Atlas. 260 p.

Ministério da Agricultura, Pecuária e Abastecimento. (2021). AGROSTAT - Estatísticas de Comércio Exterior do Agronegócio Brasileiro. Brasília: MAPA, 2020. < http://indicadores.agricultura.gov.br/agrostat/index.htm>.

Mourão, A. N. S. F.\& Siminato, M.; Campos, A. P.; Azevedo, M. H. K. (2014). Resolução de Conflitos - Fundamentos da Negociação para o Ambiente Jurídico. Saraiva. 607 p.

Marques, N. (1976). Contratos agrários inominados. Pro: Livro. 
Research, Society and Development, v. 10, n. 3, e53110313356, 2021

(CC BY 4.0) | ISSN 2525-3409 | DOI: http://dx.doi.org/10.33448/rsd-v10i3.13356

Olivier de Sardan, J. P. (2009). Development, governance and reforms: studying practical norms in the delivery of public goods and services. In: Hagberg, S.; Widmark, C. (Editores). Ethnographic practice and public aid: methods and meanings in development cooperation. Publisher: Acta Universitatis Upsaliensis. p. 101-123.

Optiz, S. C. B. \& Opitz, O. (2016). Curso completo de direito agrário. (10a ed.), Saraiva. 488 p.

Pereira, A. S. et al (2018). Metodologia da pesquisa científica. UFSM. https://www.ufsm.br/app/uploads/sites/358/2019/02/Metodologia-da-PesquisaCientifica_final.pdf 5.3).

Proença, A. M. (2007). Compêndio de direito agrário. EDUCAT.

Scavone Junior, L. A. (2010). Manual de Arbitragem. (4a ed.), Revista dos Tribunais.

Timm, A. B. (2009). Arbitragem nos Contratos - Empresariais, Internacionais e Governamentais. Livraria do Advogado Editora. 167 p. 